\title{
Social Networks and Actual Knowledge Flow in the Irish Biotech Industry
}

\author{
CHRIS VAN EGERAAT* \& DECLAN CURRAN** \\ *Department of Geography and National Institute for Regional and Spatial Analysis (NIRSA), National \\ University of Ireland Maynooth, Ireland, ${ }^{* *}$ Dublin City University Business School, Dublin, Ireland
}

(Received May 2011; accepted January 2012)

\begin{abstract}
This paper presents an analysis of networks among small and medium-sized enterprises in the Irish biotech sector. The study applies social network analysis to determine the structure of networks of company directors and inventors in the biotech sector. In addition, on the basis of interviews, this article analyses the extent of actual knowledge flow through these industry networks. The paper makes both a theoretical and methodological contribution to innovation network research. In relation to theory, the findings of the social network analysis indicate that the extent and path of knowledge flow are influenced by both the type of knowledge in question and whether the network is of a formal or informal nature. Methodologically, the results of this paper raise questions about the application of social network analysis in innovation studies.
\end{abstract}

\section{Introduction}

Recent studies of innovation detail how innovation processes are becoming increasingly complex. Individual firms can no longer rely on their internal sources of knowledge alone. Instead additional knowledge needs to be accessed from external sources. The paradigm of slowly evolving networks of organizations has come to be replaced by more fluid, amorphous and transitory structures based on alliances, partnerships and collaborations. These trends have been characterized as a transition towards "open innovation" (Chesborugh, 2003) and "distributed knowledge networks" (Asheim et al., 2007). These ideas are also prominent in territorial economic development approaches such as clusters (Porter, 1990) and national/regional system of innovation (Lundvall et al., 2002; Edquist, 2006; Cooke, 2001). These approaches emphasize the collective, collaborative processes that underlie innovation. They share a common interest in relations and networks, and the way in which these features support knowledge flow (Ingstrup et al., 2009). 
One strand of this research on innovation and territorial economic development has in recent times advocated the application of social network analysis, one of the dominant traditions in network theory (Grabher, 2006), to empirical studies in this field. This tradition has developed a range of conceptual devices, or frameworks, for analysing network structures, which can facilitate an analysis of regional innovation systems. For example, "small-world analysis" can provide important insights into the structure of the networks and their ability to support knowledge flows. One of the limitations of this type of analysis is, however, that the observed network structures are in many cases only suggestive of knowledge flow. What often remains unclear is how much actual knowledge flows through these networks, the paths involved and how these flows are influenced by network and knowledge characteristics. It is therefore important to investigate what flows across the links and the nature of this knowledge flow (Grabher, 2006).

This paper sets out to explore and explain the structures of knowledge flow and innovation among small and medium-sized enterprises (SMEs) in the Irish biotech sector. The paper makes two core contributions, one theoretical and one methodological. Theoretically, the paper contributes to our understanding of the operation of innovation networks. In this regard, the study addresses two research questions:

(1) What are the structural characteristics of knowledge and innovation networks in the Irish biotech sector and are these conducive to knowledge flow?

(2) How much knowledge actually flows across these networks, in what way and how is the level of actual knowledge flow influenced by the types of network and knowledge in question?

Secondly, with respect to the methodological contribution, the paper increases our insight into the relation between social network analysis and actual knowledge flows. Finally, the paper expands existing empirical knowledge about the extent and nature of knowledge flows in Irish biotech networks with implications for network policy.

The research design involves a mixed methodology, involving quantitative social network analysis and interviews. Social network analysis is applied to investigate the extent and structure of different types of networks in the biotech industry. In addition, interviews have been conducted with directors of biotech companies in Ireland to obtain more detailed insights into the actual knowledge flows and the character of these flows.

The second section of this paper presents a discussion of network theory and introduces a set of network and knowledge characteristics that are postulated to influence the extent and nature of actual knowledge flows in innovation networks. This is followed by a discussion of the research design and methodology in the third section. The fourth section introduces the biotech sector in Ireland. Next, the fifth section presents the findings of the social network analysis, followed by an analysis of the actual knowledge flows in the sixth section. The paper ends with conclusions and a discussion of the implications for network policies.

\section{Networks and Knowledge Flows}

The roots of the network concept and network theory go back to the end of the nineteenth century (Grabher, 2006). In broad terms, a network can be defined as a set of actors linked through a specific type of connections (Grabher, 2006). For many years, little attention was 
devoted to the role of networks in economic activity but since the early 1990s an increasing body of economists, economic sociologists and economic geographers have been focusing on the role of networks in economic activity, innovation and regional development. Network theory and analysis can lead to a better understanding of innovation and territorial economic development processes (Ter Wal \& Boschma, 2009).

A large strand of work on innovation and territorial economic development has applied social network analysis, one of the dominant approaches/traditions in network theory (Grabher, 2006). Social network analysis is based on the assumption of the importance of relationships among interacting units or actors and on the belief that units do not act independently but influence each other. Relational ties between actors are viewed as channels for transfer or flow of resources. "The unit of analysis is not the individual, but an entity consisting of a collection of individuals and the linkages among them". The social network approach provides a precise method with which to define important social concepts, a theoretical alternative to the assumption of independent social actors and a framework for testing theories about structured social relationships (Wasserman \& Faust, 1994). As an analytical tool, social network analysis provides explicit formal statements and measures of social structural properties. These tools facilitate the conceptualization of the interdependencies of behaviour and processes in networks. Structural properties are formally conceptualized in terms of nodes and linkages and characterized using "sociograms" and related measures of network structure.

Networks of relationships between social actors, be they individuals, organizations or nations, have been used extensively over the last three decades as a means of representing social metrics such as status, power and diffusion of innovation and knowledge (Watts, 1999; Kogut \& Walker, 2001). Social network analysis has yielded measures both of individual significance, such as centrality (Freeman, 1979), and of network efficiency or optimal structure (Yamaguchi, 1994).

The tradition of social network analysis has developed a range of conceptual devices, or frameworks, for analysing network structures that can facilitate an analysis of regional innovation ecosystems. Among these, "small-world analysis" offers a means by which we can gain insights into network structures and the role of these structures in facilitating (or hindering) the flow of knowledge throughout the entire network. Knowledge is assumed to flow most efficiently in networks with small-world characteristics. Where small-world characteristics are absent, these can be created by adding a relatively small number of remote links to the network where the level of local clustering is already high (Grabher, 2006). Small-world analysis has been productively applied in the context of biotech clusters. Casper and Murray (2005), for example, reported important differences in the structure of the networks in the Cambridge and Munich biotech clusters.

Although small-world analysis provides important insights into the structure of the networks and their ability to support knowledge flow, the observed structures are in many cases only suggestive of knowledge flow. They do not inform us about the extent and characteristics of the actual knowledge flow, its strategic nature or the path that knowledge takes through the network (Dahl \& Pedersen, 2004). It is therefore important to investigate what flows across the links, and in what way (Grabher, 2006). The remainder of this section will discuss these ideas in more detail.

The extent of the actual knowledge flow is likely to depend on the type of network and the type of knowledge. In relation to types of networks, a range of network forms and types can be identified (see, for example, Grabher, 2006). A broad distinction can be made 
between formal and informal networks. ${ }^{1}$ Formal networks are configured as inter-organizational alliances while informal networks are based on inter-personal ties. In our view, formal networks include both the longer-term strategic networks based on strategic alliances and joint ventures, as well as the shorter term project networks distinguished by Grabher (2006). Within these formal networks firms or institutions are linked in their totality, via, for example, joint research projects or buyer-supplier agreements.

Informal networks, on the other hand, comprise of connected persons who principally represent themselves. Because the persons are employed by firms and institutions, the links between these persons indirectly also link the institutions. In this way, the individual persons provide a pipeline for (informal) information flow between institutions. A large variety of informal networks exist, including networks of former students, professional networks, networks of friends, members of sport clubs, networks of corporate board members and so forth. Informal networks can develop on the back of, or evolve into, formal business activity, as is the case with networks of former colleagues or former business relations that have developed a friendship. However, the characteristic of such informal networks is that the network is no longer based on these (former) formal relations. Informal networks have different levels of organization or institutionalization. Some professional networks (informal from the firms' point of view) can be strongly institutionalized while other networks, for example, those based on friendship are virtually unorganized.

Formal relations are likely to be more conducive to knowledge exchange, including technical knowledge, due to the intensity of the relations. On the other hand, the intense relations and the related knowledge flows are likely to be confined to discrete subgroups involving relatively small number of actors. This makes them less conducive for knowledge diffusion through the wider network. Disagreement exists as to the salience or importance of the informal knowledge exchange for the innovation capacity and competitiveness of firms, as well as for regional clustering processes (Dahl \& Pedersen, 2004). Some contributions argue that informal networks are important channels for knowledge exchange, and that individuals in different firms and institutions informally provide each other with technical and market-related knowledge that can be of great value to the firm. Others are of the view that, although informal knowledge exchange does occur, the knowledge is generally of limited commercial or strategic value. Individuals will only exchange general knowledge that is of relatively low value to the firm, for example, information about job openings. In addition, the knowledge may not flow freely throughout the local network but, instead, circulate in smaller (sub)communities.

In relation to the type of knowledge, a distinction has been made between know-why, know-how and know-who type knowledge-with implications for the interplay between actors in innovation networks (Asheim et al., 2007). Know-why knowledge relates to natural systems and the applications of scientific laws. Know-how type knowledge involved the more technical skills, often of a tacit nature. Finally, know-who type knowledge involves knowledge about, for example, relevant business partners or sources of finance. Van Egeraat et al. (2009), based on their work on innovation processes and knowledge flows in the biotechnology industry, suggest adding a fourth, crucial, type of knowledge to the categorization-market/business knowledge. This includes knowledge of (unmet) market needs, the ability to connect particular inventions to market needs, knowledge of regulatory procedures, knowledge of raising finance and so forth. Know-why type knowledge tends to be more sensitive and can therefore be expected to flow less easily through networks, notably informal networks. At the other end of 
the spectrum, know-who and market type knowledge is far less sensitive and is therefore expected to flow more easily through networks of actors, including informal networks.

Another distinction in types of knowledge concerns the geographic content of the knowledge. In relation to this, a broad distinction can be made between knowledge about an actor's own country and knowledge about foreign countries. For example, knowledge about potential business partners at home versus knowledge about potential business partners abroad. The geographic content of the knowledge should not be confused with the location of the knowledge-local actors can be a source of knowledge about foreign locations. It is expected that actors are better informed about potential business partners at home than they are about potential business partners abroad and that the networks will play a different role or be employed differently, depending on the geographic content of the knowledge.

Finally, in relation to the path of the knowledge flow, small-world analysis implies that information will flow efficiently through the network, irrespective of the number of steps involved. However, it remains unclear how far knowledge flows through the network (Dahl \& Pedersen, 2004). We can assume that the amount of information flow is reduced with each step we become removed from the original source. In addition, the path (number of steps) is likely to be partly determined by the type of knowledge. Know-who and market type knowledge are expected to be exchanged across more steps than know why/know how type knowledge. The remainder of this paper will explore these ideas in the context of the Irish biotech industry. The next section begins by outlining the methodology employed.

\section{Methodology and Data Sources}

This paper sets out to address two main research questions: (1) What are the structural characteristics of knowledge and innovation networks in the Irish biotech sector and are these conducive to knowledge flow? (2) How much knowledge actually flows across these networks, in what way and how is the level of actual knowledge flow determined by the type of network and knowledge?

The first research question has been addressed through quantitative social network analysis. The tradition of social network analysis has developed a range of conceptual devices, or frameworks, for analysing network structures that can facilitate an analysis of regional innovation ecosystems. This research project focuses on "small-world" network analysis. Small-world analysis is concerned with the density and reach of ties between the actors in a given network. A small world is a network in which many dense clusters of actors are linked by relationships that act as conduits of control and information (Milgram, 1967; White, 1970). In keeping with the age-old exclamation "it's a small world!", the idea is that this type of network allows any two actors to be connected through a relatively small series of steps or links - despite the fact that the overall network may be quite sparse and actors may be embedded in distinct clusters. As a result, actors in the network may in reality be "closer" to each other than initially perceived.

These small-world networks, with high clustering and short global separation, have been shown by Watts (1999) to be a general feature of sparse, decentralized networks that are neither completely ordered nor completely random. Small-world network analysis offers us a means by which we can gain insights into network structures and the role of these structures in facilitating (or hindering) the flow of innovation and knowledge throughout the entire network. Watts (1999) and Kogut and Walker (2001) advocate 
comparing an observed network with a randomized network (i.e. a random graph) that has the same number of actors (nodes) and same number of relationships (links) per actor as the observed. Simulations by Watts (1999) show that the structural stability of small worlds is retained even when a substantial number of relationships are replaced with randomly generated links. The network becomes more globally connected rapidly but the dense clusters are slow to dissolve. Thus, actors in the network can strategize and, rather than being disrupted, the small-world structure is still replicated. In this way, networks that appear sparse can in fact contain a surprising degree of structure.

Small-world analysis has important application in the context of regional innovation networks. Knowledge will flow most efficiently in networks with small-world characteristics. Where small-world characteristics are absent, these can be created by adding a relatively small number of remote links to the network where the level of local clustering is already high (Grabher, 2006).

The formal description of small-world networks presented here is as per Watts (1999), with the networks represented as connected graphs, consisting of undifferentiated vertices (actors) and unweighted, undirected edges (relationships). All graphs must satisfy sparseness conditions. The small-world network analysis that follows in the next section is characterized in terms of two statistics:

Characteristic path length $(L)$ : The average number of edges that must be traversed in the shortest path between any two pairs of vertices in the graph. $L$ is a measure of the global structure of the graph, as determining the shortest path length between any two vertices requires information about the entire graph.

Clustering coefficient $(C)$ : If a vertex has $k_{v}$ immediate neighbours, then this neighbourhood defines a subgraph in which at most $k_{v}\left(k_{v}-1\right) / 2$ edges can exist (if the neighbourhood is fully connected). $C_{v}$ is then the fraction of this maximum that is realized in $v$ 's actual neighbourhood and $C$ is this fraction averaged over all vertices in the graph. In this way, $C$ is a measure of the local graph structure.

In order to determine what is "small" and "large" in this analysis, Watts (1999) determines the following ranges over which $L$ and $C$ can vary:

(1) The population size $(n)$ is fixed.

(2) The average degree $k$ of vertices is also fixed such that the graph is sparse $(k<<n)$ but sufficiently dense to have a wide range of possible structures $(k>1)$.

(3) The graph must be connected in the sense that any vertex can be reached from any other vertex by traversing an infinite number of edges.

Fixing $n$ and $k$ enable valid comparisons to be made between many different graph structures. This also ensures that the minimum value for $C$ is 0 , while the maximum value for $C$ is 1 . The sparseness condition ensures that while the network is sufficiently well connected to allow for a rich structure, each element operates in a local environment which comprises of only a tiny fraction of the entire system. Finally, the requirement that the graph is connected guarantees that $L$ is truly global statistic.

The analysis undertaken in this paper focuses on two distinct networks in the Irish biotechnology industry: (i) the formal network of researchers and related companies and (ii) the network of company directors. Formal networks of researchers have been the subject of many previous studies, notably in the context of the biotech industry (OwenSmith \& Powell, 2004, 2006; Coenen et al., 2006; Moodysson \& Jonsson, 2007). Much 
of this research is based on patent data, although some studies are using survey data providing more detailed information about the type of knowledge flows. Networks of company directors have been investigated in this paper as a form of informal networks. Directors of biotech companies tend to hold directorships on numerous corporate boards. Where this co-directorship concerns other biotech companies, the various links can be taken to represent a conduit of knowledge flow between the respective companies. Studies of corporate interlocks include Kogut and Walker (2001) and Davis et al. (2003). Myint and Vyakarnam (2004) and Myint et al. (2005) investigate the corporate board interlocks in the Cambridge biotech industry and reported the influential role of a select number of "mini clusters" in the local network.

Data collection for this paper began with an inventorization of biotech companies in Ireland (see the next section on the Irish biotech industry for details). Following this, two separate data sets were compiled for our social network analysis of the Irish biotech sector-a dataset on research networks structured by co-inventors and a set of micro-data on co-directorships.

The first data set has been compiled from patent data available from the Irish Patent Office (http://www.patentsoffice.ie/), US Patent and Trademark Office (http://www. uspto.gov/), and Esp@cenet, the European Patent Office (www.espacenet.com). By manual inspection of the patent filings of each Irish biotech company that has registered patents, we established the researchers who worked on each patent, their employer at the time and their location (whether they were foreign-based or located in Ireland).

In order to compile the second data set, a rigorous Internet search of official company websites, media sources and the online Fame dataset has been conducted. ${ }^{2}$ In this way, it can be ascertained whether a director of a given Irish biotech company also holds a directorship with another Irish biotech company. Joint directorships are then taken to represent a conduit of knowledge flow between the respective companies. ${ }^{3}$ We have endeavoured to verify the database through consultation with industry experts. All data were analysed with UCI-NET social network analysis software.

The second research question deals with the actual knowledge flows-how much knowledge actually flows across the networks, in what way and how is the level of actual knowledge flow determined by the type of network and knowledge? To address this question, interviews were conducted with members of the two networks. The most networked companies were identified on the basis of the findings of the social network analysis and 10 were selected for interview. The interviewees were shown the sociograms and invited to provide information regarding the knowledge flows (operating through the two networks) with directly and indirectly linked firms and institutions. The semi-structured questionnaire included questions regarding, amongst others: the type of knowledge (technical knowledge versus know who/market knowledge; ${ }^{4}$ geographical content of the knowledge); the strategic importance of the knowledge (rated on a five-point Likert scale); the actual persons in the companies involved in the link; the process of the knowledge flow and the path of the knowledge (number of steps involved).

In addition, the interviews were used to obtain information about the extent of knowledge exchange between the companies with all other biotech companies (irrespective of whether or not these were identified in the sociograms related to the two networks). For this purpose, the interviewees were shown a list of all biotech companies in Ireland and asked to provide information regarding the knowledge flow. This part of the questionnaire involved the same set of questions as outlined above. The companies were asked to 
provide information about both inward and outward knowledge flow. The interviews were conducted with one director of each of the companies interviewed.

\section{The Irish Biotech Industry}

The development of the "modern" biotech sector" in Ireland took off in earnest in the 1990 s, although substantial employment growth only occurred in the 2000s due to the establishment of a number of foreign-owned biopharmaceutical manufacturing plants. The development of the indigenous industry has been shaped by two distinct evolutionary processes (Curran et al., 2011). The industry has experienced a wave of private sector spinoff firms emanating from Elan, Ireland's largest indigenous biotech multinational, in the aftermath of a US Securities and Exchange Commission investigation in 2002 into the company's accounting practices. Elan's subsequent divesture of biotechnology assets led to the formation of 12 spin-off firms during the period between 2002 and 2008 alone.

In parallel with this wave of Elan spin-offs, since the mid-1990s Ireland has benefited from substantial public sector investment which has significantly enhanced the biotech research performance of Irish universities (van Egeraat \& Breathnacht, 2012; van Egeraat \& Barry, 2009). In 1998, the Irish government launched the Programme for Research in the Third-Level Institutions (PRTLI) and Science Foundation Ireland (SFI), which since its inception has invested $€ 865$ million (including exchequer and private matching funds) into strengthening national research capabilities via investment in human and physical infrastructure. ${ }^{6}$ In addition, a significant empowerment of Technology Transfer Offices of the Irish universities has occurred over the last decade, in tandem with a rapid realignment of university research activities (Geoghegan \& Pontikakis, 2008).

Partly due to the lack of official statistics and partly due to the ambiguous nature of the definition it is difficult to determine the size of the Irish biotech industry. Our "universe" of firms in the modern biotech industry in Ireland was based on existing survey material (InterTrade Ireland, 2003), the list of firms included on the "Biotechnology Ireland" website (hosted by Enterprise Ireland), information from interviews with industry experts and Internet search. The final list included 80 biotech firms. Biopharmaceuticals and biodiagnostics are the largest subsectors with $64 \%$ of companies. The Irish biotech sector includes 28 foreign-owned and 52 indigenous companies.

Nearly all the foreign-owned companies are subsidiaries of multinationals with a strong manufacturing focus, although the biopharmaceutical manufacturing plants can have a substantial process development component (van Egeraat, 2010). The indigenous companies are concentrated in biopharmaceuticals and biodiagnostics. However, the majority of these firms are very small, early stage, start-up or campus companies. As regards company size, the data are incomplete. What we do know is that all but two of the indigenous companies are SMEs. It is estimated that the majority of indigenous companies on the list are micro-enterprises, employing less than 10 staff. Most of the indigenous biopharmaceutical companies are still at an embryonic stage, operating out of university labs and less than a handful would have brought molecules beyond pre-clinical trials.

\section{Structural Properties of Two Networks}

Figure 1 presents a sociogram of the network connections in the Irish biotech industry, using data on directorships. Some directors are director of more than one biotech 


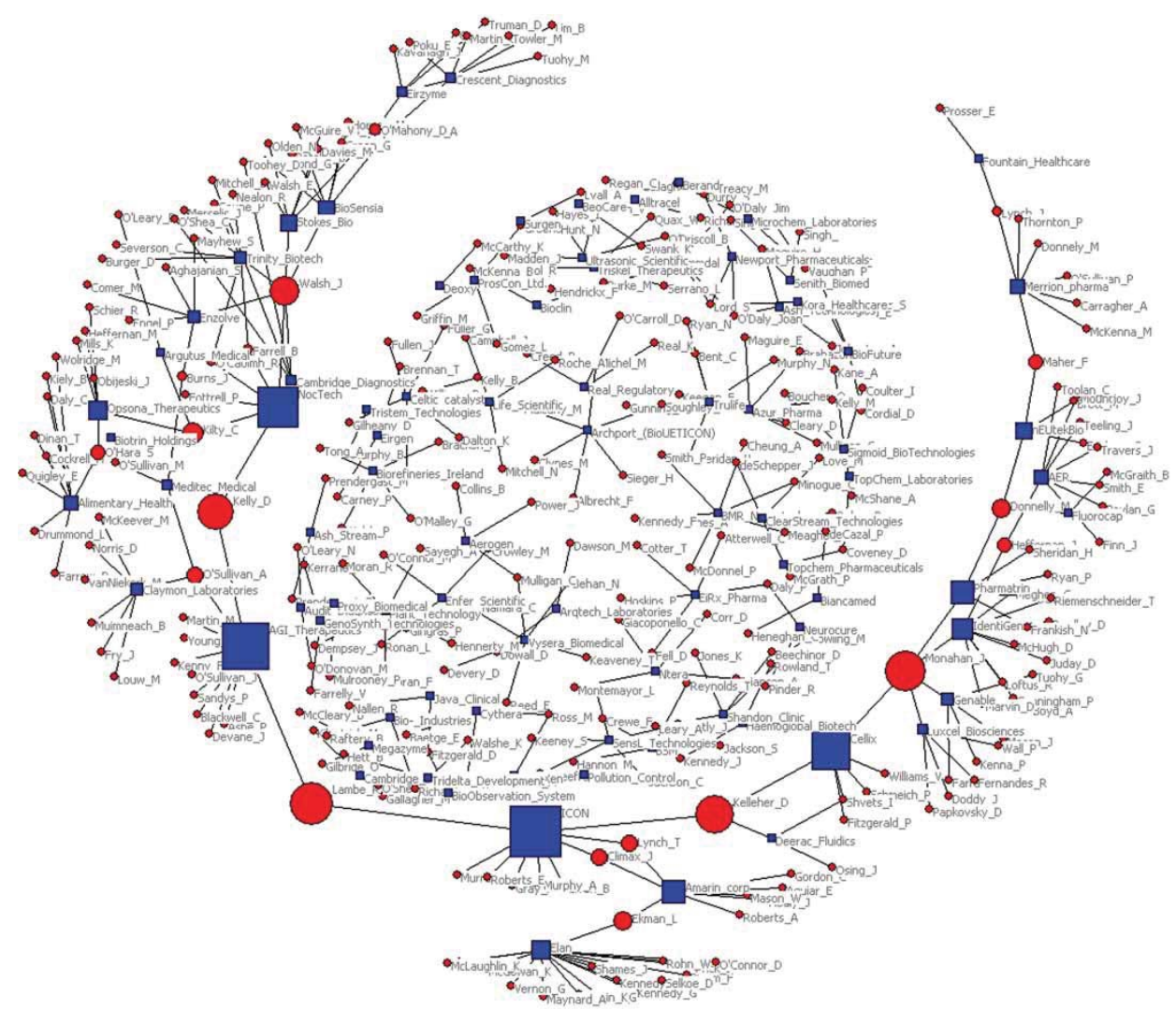

Figure 1. Network of Irish biotech directors and companies, based on directorship data. Note: Rectangles indicate firms; circles indicate directors.

company, providing links or ties in the network which can support information flow. This sociogram is characterized by the presence of one distinct chain of companies linked to each other through less than 10 directors. This chain of connected companies and prominent directors exhibit strong "betweenness" centrality (Freeman, 1979), as indicated in the sociogram by the sizes of their nodes. Figure 2 presents a sociogram of the network connections in the Irish biotech industry, but in this case the network of Irish biotech companies and researchers, as indicated by patent data. Unlike the directorship sociogram (Figure 1), this patent-based sociogram is strongly influenced by the presence of one central company, Elan, as well as a number of Elan's subsidiaries. While a handful of individual researchers do exhibit a degree of "betweenness" centrality, these individual researchers are linked to only two or three biotech companies within the network.

On the face of it, the sociograms would suggest that the networks have a low density. However, as discussed in the methodology section, the structure of the networks may be such that despite low overall density, the small-world characteristics of short path length and high clustering may still be features of the network. This would suggest that rather than being a sparse network unsuited for swift flows of knowledge, there may actually be potential for rapid diffusion of knowledge through the network if the right actors 


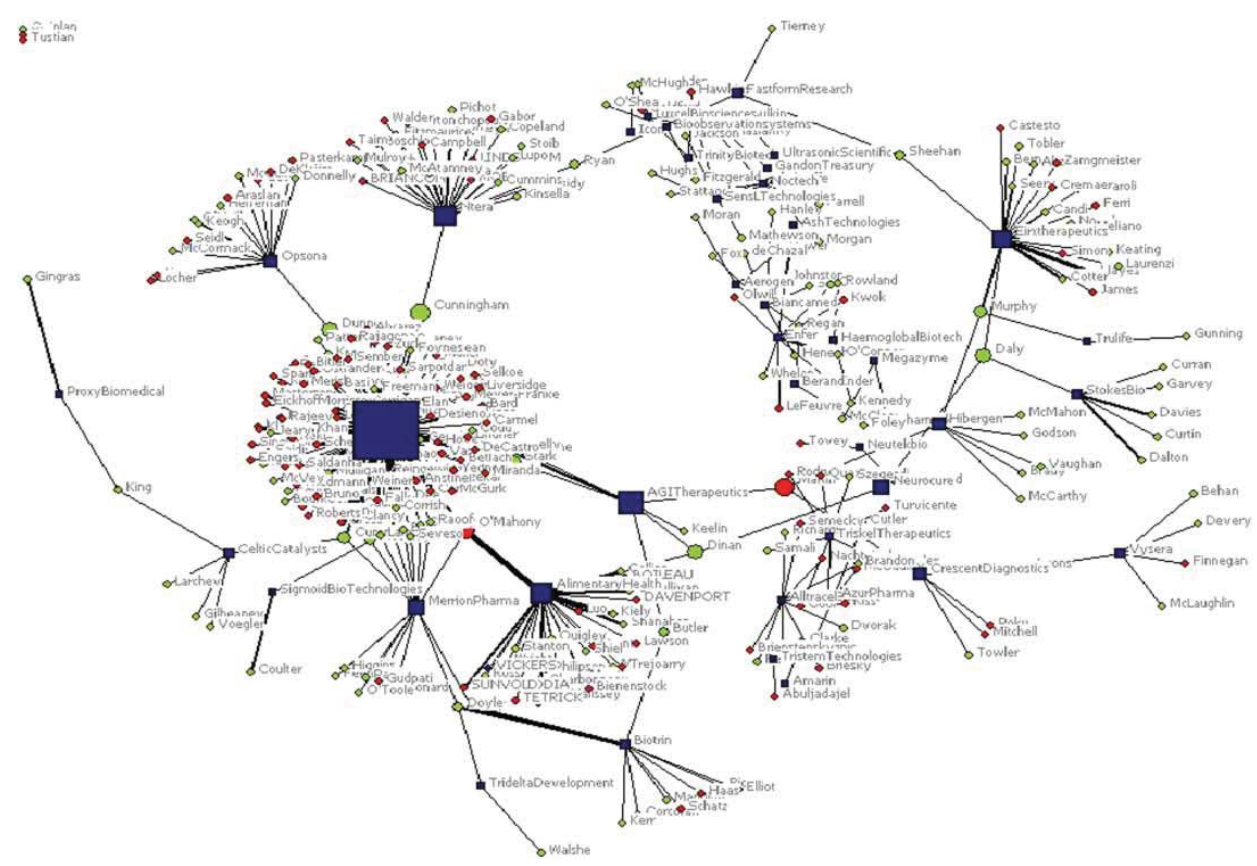

Figure 2. Network of Irish biotech researchers and companies, based on patent data. Note: Rectangles indicate firms; circles indicate directors. Light-shaded circles indicate researchers based in Ireland, while dark-shaded circles indicate researchers based abroad.

are targeted. Using both data sets, both informal networks and formal networks can be analysed and their conduciveness to knowledge flow compared. The results of the small-world network analysis are now presented.

Table 1 presents the results from the Irish biotech network of directors and companies, analysing the directors and companies separately (i.e. deconstructing a 2-node network

Table 1. Irish biotech industry directors and companies (via directorships) network statistics

\begin{tabular}{lcc}
\hline Variable & Directors & Companies \\
\hline Density & & \\
Density (for all directors/firms) & 0.018 & 0.016 \\
Total no. of ties & 1622 & 118 \\
Average no. of ties (between those connected) & 5.5 & 2.7 \\
Clustering & 0.948 & 0.669 \\
Cluster coefficient & 0.039 & 0.062 \\
Random cluster coefficient & & 2.912 \\
Path length & 3.538 & 4.111 \\
Average path length among those connected & 3.127 & \\
Random average path length &
\end{tabular}

Notes: No. of directors: 302; No. of firms: 86; No. of connected firms: 43. 
into its constituent 1-node networks). While directors may be connected to each other by virtue of being on the board of the same company, this type of intra-company link is avoided by analysing the company-only 1-node network. Thus, presenting the results of both 1-node network analyses serves as a useful robustness check. In keeping with the formal description of small-world networks presented in the methodology section, two central findings can be gleaned from Table 1. First, it is clear that both directors and companies are highly clustered ( $C=0.948$ and 0.669 , respectively). This is particularly evident when compared with the low degree of clustering generated by a random network with the same number of nodes and ties as the highly structured observed networks $(C=0.039$ and 0.062 , respectively). Second, though the director and company networks are highly clustered, they are not characterized by long path lengths. This is in keeping with Watts' (1999) findings that even as a network moves from a structured to a random graph, the path length decreases rapidly but the clustering is persistent

Comparable results emanating from the network of Irish biotech researchers and the network of Irish biotech companies via patents are presented in Table 2. These results refer to a formal network in the Irish biotech industry. Once again, the salient findings are those of high clustering and short path lengths for both the researcher and company networks. However, in this instance, the company network is noticeably less clustered via patents than it was through directors. This result would suggest that, in keeping with the postulation, this formal network is less conducive to knowledge flow than the informal network of company directors.

Finally, Table 3 presents a comparison of small-world networks identified in a range of existing studies and allows us to assess "how small" the networks in the Irish biotech industry are. The small-world network statistics of the Irish biotech industry are compared with comparable small-world statistics presented in the Casper and Murray (2005) study of past career affiliation networks (i.e. networks formed by previous employment) among scientific employees in two European biotechnology clusters, Cambridge, UK, and Munich, Germany. Comparison across the networks illustrates once again the presence of strong small-world characteristics within the Irish Biotech informal director network and the network of companies connected via directors, as well as the lesser degree of

Table 2. Irish biotech industry researcher and companies (via patents) network statistics

\begin{tabular}{lcc}
\hline Variable & Researchers & Companies \\
\hline Density & & \\
Density (for all researchers/firms) & 0.163 & 0.041 \\
Total no. of ties & 16,110 & 64 \\
Average no. of ties (between those connected) & 52.5 & 2.78 \\
Clustering & 0.975 & 0.439 \\
Cluster coefficient & 0.570 & 0.099 \\
Random cluster coefficient & & 2.091 \\
Path length & 2.013 & 3.264 \\
Average path length among those connected & & 256 \\
Random average path length &
\end{tabular}

Notes: No. of researcher: 315; connected researchers: 307; No. of firms (that have registered patents): 40; connected firms: 23. 
Table 3. A comparison of small-world network statistics

\begin{tabular}{|c|c|c|c|c|c|c|}
\hline \multirow[b]{2}{*}{ Network } & \multicolumn{2}{|c|}{ Path length } & \multicolumn{2}{|c|}{ Clustering } & \multicolumn{2}{|c|}{$\begin{array}{l}\text { Actual-to-random } \\
\text { ratio for: }\end{array}$} \\
\hline & Actual & Random & Actual & Random & Length & Clustering \\
\hline Irish biotech directors & 3.538 & 3.127 & 0.948 & 0.039 & 1.131 & 24.31 \\
\hline $\begin{array}{l}\text { Irish biotech companies (via } \\
\text { directors) }\end{array}$ & 2.912 & 4.111 & 0.669 & 0.062 & 0.708 & 10.79 \\
\hline Irish biotech researchers & 2.091 & 2.013 & 0.975 & 0.570 & 1.039 & 1.711 \\
\hline Irish biotech companies (via patents) & 2.256 & 3.264 & 0.439 & 0.099 & 0.691 & 4.434 \\
\hline Cambridge biotech career affiliation ${ }^{\mathrm{a}}$ & 3.701 & 2.312 & 0.855 & 0.126 & 1.601 & 6.786 \\
\hline Munich biotech career affiliation $^{a}$ & 3.578 & 2.085 & 0.835 & 0.148 & 1.716 & 5.642 \\
\hline
\end{tabular}

${ }^{\mathrm{a}}$ Casper and Murray (2005).

clustering in the formal network of Irish biotech researchers and the network of Irish biotech companies via patents.

Although not relevant to the social network analysis exercise, the data set contains spatial data that anticipate one theme of the discussion of the actual knowledge flows in the following section. The knowledge networks are clearly not bounded by national borders. The formal network of investigators (patents) involves both local and non-local actors. In Figure 2, the light-shaded circular nodes denote investigators located in Ireland and the dark-shaded circular nodes denote investigators located in other countries. Many companies owned patents that involved only Irish-based investigators. At the same time, $35 \%$ of the companies owned at least one patent that was linked to foreign-based investigators, although only 10 companies and 4 universities owned at least one patent that was linked to both local and foreign-based investigators. The informal network of company directors is far less global in character. Only a small number of Irish companies have a non-Irish director on their board, although quite a number of Irish directors hold a directorship of a company based abroad.

\section{Actual Knowledge Flows}

The social network analysis provides insights into the structure of the networks in question and their ability to support knowledge flow. However, the structures are only suggestive of knowledge flow. This section gives an account of the amount and strategic importance of the knowledge that actually flows through the networks in the Irish biotech industry, the paths involved and how the flows are influenced by network and knowledge characteristics. To answer these questions in relation to the two focal networks, interviews were conducted with members of the two networks. The interviewees were first shown the sociograms and invited to provide information regarding the knowledge flows (operating though the network) with directly (one step removed) and indirectly (multiple steps removed) linked firms and institutions. The findings are summarized in Table 4.

The interviews reveal that the two particular networks are poorly exploited, although to different extents. With respect to the formal network of investigators (patents), we found no evidence of companies obtaining knowledge from either the directly or indirectly linked companies (resulting from this particular network). In line with expectations 
Table 4. Level of exploitation of the two focal networks for different types of knowledge

\begin{tabular}{|c|c|c|c|c|}
\hline & \multicolumn{2}{|c|}{ Single step } & \multicolumn{2}{|c|}{ Multi-step } \\
\hline & National & International & National & International \\
\hline \multicolumn{5}{|c|}{ Network of investigators (formal) } \\
\hline Technical knowledge & - & - & - & - \\
\hline Know-who knowledge & n.a. & n.a. & - & - \\
\hline Market/business knowledge & - & - & - & - \\
\hline \multicolumn{5}{|c|}{ Network of directors (informal) } \\
\hline Technical knowledge & - & - & - & - \\
\hline Know-who knowledge & n.a. & n.a. & - & + \\
\hline Market/business knowledge & - & + & - & + \\
\hline
\end{tabular}

Notes: The symbols in this table are only indicative of the intensity of the different types of information flow. "-" denotes limited or no exploitation; "+" denotes substantial exploitation.

based on the social network analysis, the informal network of directors involves a greater amount of knowledge flow, although the intensity of the flow depends on the type of knowledge and geographical content of the knowledge content. In terms of the type of knowledge, apart from one case, the flows do generally not involve technical knowledge concerning the directly linked firms. In fact, three interviewees pointed out that they had signed confidentiality agreement which prevented them from divulging strategic information about their company to other companies.

The network of directors played a more important role in relation to know-who type and general business knowledge, although the geographical content of the knowledge is a factor here. All interviewees stated that their firms had received valuable knowledge of this type from their directors. However, only one of the interviewees argued that the link with the directorship network played a significant role in the identification of, and/ or introduction to, relevant actors in the Irish market. On the other hand, interviewees pointed out that directorship networks do play a more important role at the international scale. Six of the interviewed companies have corporate interlocks with firms outside of Ireland and these are frequently used to obtain information about firms or markets abroad. "If this was a European analysis or a global one, then it would be much more likely that I would be skipping through directors. Because it is not my local area, I would rely far more heavily on those fellow directors in the US to point me in the right direction" (Interview biotech company).

Apart from the firms linked by the two networks, the interviewed companies did obtain knowledge from other local firms. To investigate the extent and character of the overall knowledge flow, companies were asked to provide information about the companies or institutions they had turned to for either technological advice or know-who/market/ general business type knowledge during the last 5 years. Here we found evidence of more substantial knowledge flows. Here too, the type of knowledge and type of network had an effect on the extent of the knowledge flow and its path.

With respect to technical advice all interviewed companies had been in contact with between three and nine other Irish companies/institutions. Universities accounted for $58 \%$ of these contracts. All interviewed companies had technology-related contact with several Irish universities and all universities were mentioned by at least two respondents. 
However, in all but two cases, the amount of technical advice or knowledge flow was very limited. These links involved relatively standard service provision such as analytical services, clinical trial work by clinical research organizations and so forth. It is debatable whether this can be considered knowledge flow. In fact, interviewees themselves expressed unease with linking these types of contact with knowledge flow. In addition, in most cases, the strategic importance is limited. The average score for the strategic importance of the cases was 2.5 on a five-point Likert scale.

With respect to know-who type knowledge, we found evidence of networks facilitating the identification of relevant actors. However, the geographical content of the knowledge was an important factor here. The number of instances of companies intentionally consulting other local companies for know-who/market type knowledge concerning the local business environment was relatively small. Interviewees typically mentioned only one or two such cases. However, again all interviewees expressed that the networks did play a more important role in obtaining know-who type knowledge about actors in other countries (quantitative data on such links were not collected).

The limited level of multi-step flows of know-who type knowledge concerning the Irish business environment does not mean that the local networks are not exploited or not valuable. Rather, the limited level of such flows reflects the fact that actors are generally very well informed about and connected to the Irish scene and do not need to consult the network for know-who type information about, or introductions to, actors in Ireland. The level of personally embedded know-who type knowledge is, in fact, for a large part, the result of a long-term participation in a range of local networks. Interviewees pointed out that they personally knew and could directly (single step) contact a large part of the Irish biotech scene on the basis of these relations.

Again, the networks are extensively exploited to facilitate the multi-step flow of knowwho and business type knowledge concerning other countries. Informal network relations were by far the dominant type of network supporting this type of knowledge flow. A range of networks are at play, including professional networks of individuals (which include former formal relations that had evolved into informal relations), student networks and social networks. Most important are the personal professional networks, built up over years, linking former and current colleagues and commercial contacts. "The most important channel is related to people moving on" (Interview biotech company). During their careers, individual actors come into contact with a large section of the Irish biotech industry. Although some of the relations are closer than others, most facilitate contact and information flow over a long period. As one interviewee put it: "We were collaborating with [this company] on some of their technology. That is 10 years ago. But it is still easier to pick up the phone, asking for somebody by name, if you have met the person" (Interview biotech company). Another important network is formed by university alumni. "University College Dublin (UCD) is part of the extended diaspora from my Trinity College days. So, colleagues from Trinity College who are now based at UCD. We retain a fairly open channel with them and indeed other post-docs" (Interview biotech company).

The informal network of company directors is one part of this broader set of partly overlapping informal networks linking the Irish biotechnology firms. The directorship network is a relatively small element in the overall informal network constellation. Other informal networks, notably the professional networks of the individuals and network of university alumni involve many more relations and therefore play a far greater role in knowledge flow. 


\section{Conclusions}

This paper sets out to make both a theoretical and a methodological contribution to the field of innovation network research. The theoretical contribution focuses on two research questions: (1) What are the structural characteristics of knowledge and innovation networks in the Irish biotech sector and are these conducive to knowledge flow? (2) How much knowledge actually flows across these networks, in what way and how is the level of actual knowledge flow influenced by the types of network and knowledge in question?

The social network analysis conducted in this paper shows that both the formal network of researchers and the informal network of company directors have small-world characteristics, suggesting that they are conducive to knowledge flow. In line with the expectations, the structure of the informal network is more conducive to knowledge flow than the structure of the formal network.

The results of the subsequent analysis of actual knowledge flows are surprising, at least at first glance. The interviews show that the two particular networks are poorly exploited, although the informal network is somewhat better exploited than the formal network. However, to a large extent, this can be brought back to the specific networks under consideration. The interview data about knowledge flows between all actors in the Irish biotechnology industry (irrespective of whether or not these actors were identified in the sociograms related to the two focal networks) provide evidence of more substantial knowledge flows.

In line with the postulations outlined in the second section, the extent of the knowledge flows and the path of the flows depend on the type of network and the type of knowledge. In terms of the type of network, informal relations and networks dominate as a medium for knowledge flow. In relation to the disagreement as to the salience or importance of the informal exchange for the competitiveness of firms (Dahl \& Pedersen, 2004), as outlined in the second section, our findings suggest that the informal exchange can involve knowledge of significant commercial or strategic value.

As regards type of knowledge, this paper stresses the importance of distinguishing between types of knowledge flow and expands the typology of knowledge flows developed by Asheim et al. (2007). This expanded typology allowed us to undertake a detailed assessment of each type of knowledge flow in both the formal and informal knowledge networks under consideration in this study. We found limited evidence of technical knowledge flow and that the technical knowledge which was exchanged was of limited strategic value. The networks were more intensively exploited for the know-who/market type knowledge. Where the extant literature provides little attention to the geographical content of the knowledge and the path of the flow, this paper identifies these as important distinguishing factors. For example, where know-who market type knowledge concerns knowledge about Ireland, the flows tend to be a single step, simply because the large number of direct local network relations of the actors. We did find more evidence of multiple-step flow of know-who knowledge about foreign locations.

As regards the methodological contribution, the results of this paper raise questions about the application of social network analysis in innovation studies. Notably, innovation networks identified through social network analysis using patent data may involve relatively little actual information flow, certainly after these networks are devolved. In addition, in contrast to the implicit assumption of the small-world analysis, the results 
of this study suggest that the much knowledge, notably technical knowledge, flows not beyond one or two steps.

The insights into the structural characteristics of the knowledge and innovation networks and the actual level of knowledge flow of the Irish biotechnology sector yield some lessons regarding network policy. First, rather than focusing on individual formal networks, network policy in the Irish biotech industry should involve the entire social worlds of firms - the entire constellation of informal social networks, including professional networks of individuals, university alumni and social networks.

Secondly, the Irish Biotech sector appears to be intensively networked and the structures of the networks are conducive to knowledge flow. The focus of network policy may therefore be less on the establishment/expansion of networks and more on the better exploitation and use of existing networks.

Thirdly, existing informal networks in the biotech industry involve limited technical knowledge flow and diffusion. This is partly due to efforts to protect firm-specific assets and intellectual property. There is, however, scope to better exploit the informal network for the flow of less-sensitive technological knowledge. One could think of a national online science forum for biotechnology scientists and technicians. Here biotechnology scientists and technicians in companies and universities could ask for advice about, and interactively discuss, scientific and technical problems.

Fourthly, network policy can play a particularly valuable role in stimulating the flow of know-who and business/market type knowledge related to foreign locations. One suggestion would be to establish an online forum for regional actors (in universities; research institutions and private enterprise) to consult each other on a reciprocal basis about the location of non-local actors, sources of knowledge and relevant intellectual property.

\section{Acknowledgements}

This paper draws on research conducted by The OPAALS Network of Excellence (Open Philosophies for Associative Autopoietic Digital Ecosystems), funded by the EU Framework Programme, Priority 2 - Information Society Technologies. The authors would like to thank the partners for their comments on previous drafts of this paper. In addition we wish to thank Jerker Moodysson and Bjorn Asheim at the Centre for Innovation, Research and Competence in the Learning Economy (CIRCLE), Lund University for giving us access to their interview questionnaires and Sarah Maloney for her excellent research assistance.

\section{Notes}

1. The formal vs. informal distinction is closely related to the distinction between structural social capital and relational social capital as recognized by Nahapiet and Ghoshal (1998) and applied in the context of the Cambridge biotech industry by Myint and Vyakarnam (2004).

2. The Fame data set provides ownership, governance and financial data on UK and Irish companies. For further details, see www.bvdinfo.com/Products/Company-Information/National/Fame.

3. This data set also contains information on the founders of each company, serial entrepreneurs who form numerous companies and spin-off companies. The database also identifies whether these spin-off companies emerged from existing private companies or universities. The date of establishment of all spin-offs and existing companies is also included in the data set. 
4. On the basis of the pilot interview, it was decided to condense know-why and know-how type knowledge into a single, category named "technical knowledge".

5. The OECD (2006) defines biotech as the application of science and technology to living organisms, as well as parts, products and models thereof to alter living or nonliving materials for the production of knowledge, goods and services. In order to narrow the definition to "modern" biotech, the OECD employs a list-based definition that includes various techniques and activities: synthesis, manipulation or sequencing of DNA, RNA or protein; cell and tissue culture and engineering; vaccines and immune stimulants; embryo manipulation; fermentation; using plants for cleanup of toxic wastes; gene therapy; bioinformatics, including the construction of databases, and nanobiotech.

6. See www.hea.ie for further details.

\section{References}

Asheim, B., Boschma, R., \& Cooke, P. (2007) Constructing regional advantage: Platform policy based on related variety and differentiated knowledge bases. Utrecht University Working Paper.

Casper, S. \& Murray, F. (2005) Careers and clusters: Analyzing the career network dynamics of biotechnology clusters, Journal of Engineering Technology Management, 22(1), pp. 51-74.

Chesborugh, H. (2003) Open Innovation: The New Imperative for Creating and Profiting from Technology (Boston: Harvard Business School Press).

Coenen, L., Moodysson, J., Ryan, C., Asheim, B. \& Phillips, P. (2006) Comparing a pharmaceutical and an agrifood bioregion: On the importance of knowledge bases for socio-spatial patterns of innovation, Industry and Innovation, 13(4), pp. 393-414.

Cooke, P. (2001) Regional innovation systems, clusters and the knowledge economy, Industrial and Corporate Change, 10(4), pp. 945-974.

Curran, D., O'Gorman, C., \& van Egeraat, C. (2011) New entrants and inherited competence: The evolution of the Irish biotech sector, NIRSA Working Paper Series, no. 66. Available at http://www.nuim.ie/nirsa/research/ documents/WP66-New_Entrants_and_Inherited_Competence.pdf (accessed 1 June 2012).

Dahl, M. \& Pedersen, C. (2004) Knowledge flow through informal contacts in industrial clusters: Myth or reality, Research Policy, 33(10), pp. 1673-1686.

Davis, G., Yoo, M. \& Baker, W. (2003) The small world of the American corporate elite, 1998-2001, Strategic Organisation, 1(3), pp. 301-326.

Edquist, C. (2006) Systems of innovation: Perspectives and challenges, in: J. Fagerberg, D. Mowery \& R. Nelson (Eds) The Oxford Handbook of Innovation, pp. 181-209 (Oxford: Oxford University Press).

van Egeraat, C. (2010) The scale and scope of process R\&D in the Irish pharmaceutical Industry, Irish Geography, 43(1), pp. 35-58.

van Egeraat, C. \& Barry, F. (2009) The pharmaceutical industry over the boom period and beyond, Irish Geography, 42(1), pp. 23-44.

van Egeraat, C. \& Breathnacht, P. (2012) The drivers of transnational subsidiary evolution: The upgrading of process R\&D in the Irish pharmaceutical industry, Regional Studies, 46(9), pp. 1153-1167.

van Egeraat, C., O'Riain, S. \& Kerr, A. (2009) Social and spatial structures of collaboration and innovation in the knowledge economy. Deliverable 11.2 for EU FP6 OPAALS Research Project. Available at http://www. nuim.ie/nirsa/research/documents/WP_egeraat_orian_kerr.pdf (accessed 1 June 2012).

Freeman, L. C. (1979) Centrality in social networks: Conceptual clarification, Social Networks, 1(3), pp. 215239.

Geoghegan, W. \& Pontikakis, D. (2008) From ivory tower to factory floor? How universities are changing to meet the needs of industry, Science and Public Policy, 35(7), pp. 462-474.

Grabher, G. (2006) Trading routes, bypasses and risky intersections: Mapping the travels of networks, progress human geography, Progress in Human Geography, 30(2), pp. 163-189.

Ingstrup, M., Freytag, P. \& Damgaard, T. (2009) Cluster initiation and development: A critical view from network perspective. Paper presented at the Conference Euromed Management, France.

Intertrade Ireland. (2003) Mapping the Bio-Island (Newry: InterTradeIreland).

Kogut, B. \& Walker, G. (2001) The small world of Germany and the durability of national networks, American Sociological Review, 66(3), pp. 317-335.

Lundvall, B. A., Johnson, B., Andersen, E. S. \& Dalum, B. (2002) National systems of production, Innovation and Competence Building, Research Policy, 31(2), pp. 213-231. 
Milgram, S. (1967) The small world problem, Psychology Today, 2, pp. 60-67.

Moodysson, J. \& Jonsson, O. (2007) Knowledge collaboration and proximity: The spatial organization of biotech innovation projects, European Urban and Regional Studies, 14(2), pp. 115-131.

Myint, Y. M. \& Vyakarnam, S. (2004) Multiple directorships in Cambridge hi-tech cluster: Implications for policy and research. Paper presented at the 27th Institute of Small Business Affairs National Conference, Teeside, UK.

Myint, Y. M., Vyakarnam, S. \& New, M. J. (2005) Effect of social capital in new venture creation: The Cambridge high-technology cluster, Strategic Change, 14(3), pp. 165-177.

Nahapiet, J. \& Ghoshal, S. (1998) Social capital, intellectual capital, and the organizational advantage, Academy of Management Review, 23(2), pp. 242-266.

OECD (2006) Biotechnology Statistics 2006 (Paris: Organisation for Economic Cooperation and Development).

Owen-Smith, J. \& Powell, W. (2004) Knowledge networks as channels and conduits: The effects of spillovers in the Boston biotechnology community, Organisation Science, 15(1), pp. 5-21.

Owen-Smith, J. \& Powell, W. (2006) Accounting for emergence and novelty in Boston and Bay Area biotechnology, in: P. Braunerhjem \& M. Feldman (Eds) Technology-Based Industrial Development, p. 61 (Oxford: OUP).

Porter, M. (1990) The Competitive Advantage of Nations (London: Macmillan).

Ter Wal, A. \& Boschma, R. (2009) Applying social network analysis in economic geography: Framing some key analytic issues, Annals of Regional Science, 43(3), pp. 739-756.

Wasserman, S. \& Faust, K. (1994) Social Network Analysis: Methods and Applications (New York: Cambridge University Press).

Watts, D. (1999) Networks, dynamics, and the small-world phenomenon, American Journal of Sociology, 105, pp. 493-527.

White, H. (1970) Search parameters for the small world problem, Social Forces, 49(2), pp. 259-264.

Yamaguchi, K. (1994) The flow of information through social networks diagonal—free measures of inefficiency and the structural determinants of inefficiency, Social Networks, 16(1), pp. 57-86. 